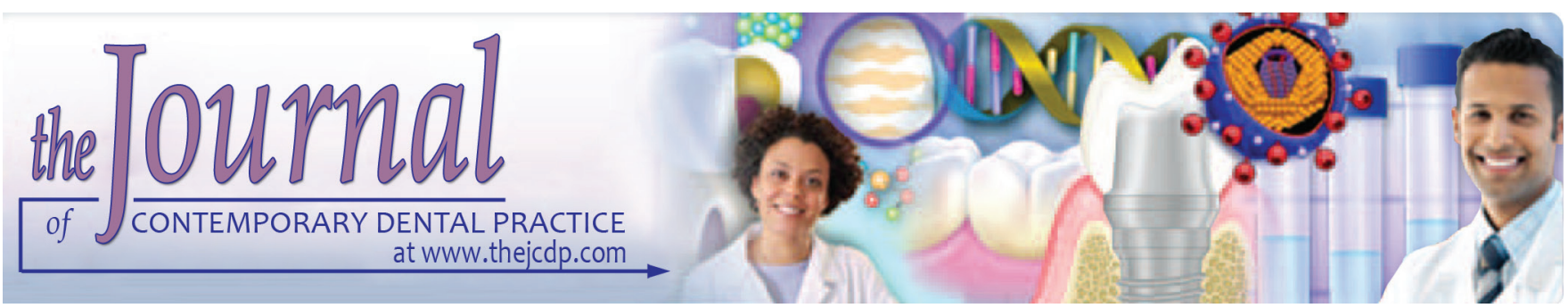

\title{
Prevalence and Pattern of Mandibular Third Molar Impaction in Eritrean Population: A Retrospective Study
}

\author{
${ }^{1}$ V Raj Kumar, ${ }^{2}$ Priya Yadav, ${ }^{3}$ Efrem Kahsu, ${ }^{4}$ Farhana Girkar, ${ }^{5}$ Rajnish Chakraborty
}

\begin{abstract}
Introduction: The most commonly impacted tooth in the oral cavity is the mandibular third molar. Various etiologic factors have been suggested for impacted mandibular third molars. The pattern and prevalence of impacted mandibular third molars vary with different population and region. This study throws light on the prevalence and pattern of impacted mandibular third molars in Eritrea, East Africa. This is the first reported study regarding the same from Eritrea.
\end{abstract}

Aim: To assess the prevalence and pattern of impacted mandibular third molars in the population of Eritrea, East Africa by conducting a retrospective study from January 2009 to January 2014.

Materials and methods: This study was conducted in the Department of Oral and Maxillofacial Surgery, Orotta School of Medicine and Dental Medicine and the Orotta Referral Medical and Surgical Hospital, Asmara, Eritrea. A total of 1,813 clinical and radiographic records [orthopantomograms] were assessed and 276 cases were selected for the study as per the inclusion criteria. They were evaluated for the frequency among the various age groups, gender and region along with the sides affected, angulation and level of impaction. The presence of systemic conditions and associated pathologies was also assessed according to the type of impaction.

Results: The average age of these patients in the study was found to be 30 years, with the 20 to 30 years age group being

\footnotetext{
${ }^{1}$ Division of Oral and Maxillofacial Surgery, College of Dentistry Jazan University, Jazan, Kingdom of Saudi Arabia

${ }^{2}$ Department of Periodontics, ESIC Dental College \& Hospital New Delhi, India

${ }^{3}$ Orotta School of Medicine and Dental Medicine, Asmara, Eritrea

${ }^{4}$ Department of Oral and Maxillofacial Surgery, Institute of Dental Studies and Technologies, Ghaziabad, Uttar Pradesh, India

${ }^{5}$ Institute of Dental Studies and Technologies, Ghaziabad, Uttar Pradesh, India

Corresponding Author: $\vee$ Raj Kumar, Division of Oral and Maxillofacial Surgery, College of Dentistry, Jazan University Jazan, Kingdom of Saudi Arabia, Phone: +966593301265 e-mail: drraj.drraj@gmail.com
}

the most affected (67.4\%). Females (53.3\%) were affected more than the males (46.7\%). People from the Asmara region showed significantly more prevalence $(79.7 \%)$ than the adjoining areas (20.3\%). Mesioangular impaction was the most common angulation with a definite relationship to the age groups $(p=0.032)$. The level of impaction had no significant relationship to the age groups, gender, or region, although class I position A was found to be the most common type. Mesioangular class I position A impaction showed an apparent relationship with underlying systemic conditions, but it was statistically insignificant. Mesioangular impaction was found to be associated with the most number of pathologies $(p=0.001)$.

Conclusion: The prevalence of mandibular impaction was less in Eritrea (15.2\%) compared with other populations. This study provides useful baseline data for the prevalence and pattern of mandibular impaction in the Eritrean population.

Clinical significance: This study throws light on the pattern, type, and frequency of mandibular impacted teeth as per age, sex, and region among the population of Eritrea.

Keywords: Eritrea, Impacted mandibular third molar, Pattern, Prevalence.

How to cite this article: Kumar VR, Yadav P, Kahsu E, Girkar F, Chakraborty R. Prevalence and Pattern of Mandibular Third Molar Impaction in Eritrean Population: A Retrospective Study. J Contemp Dent Pract 2017;18(2):100-106.

Source of support: Nil

Conflict of interest: None

\section{INTRODUCTION}

The term impaction is derived from the Latin word "impactus." In normal usage, it implies an organ or structure, which because of an abnormal mechanical condition has been prevented from assuming its normal position. Rounds ${ }^{1}$ defined impaction as a condition in which the tooth is embedded in the alveolus, so that, its further eruption is prevented. William ${ }^{2}$ stated impacted tooth as one which is completely or partially unerupted and is positioned against another tooth, bone, or soft 
tissue so that its further eruption is unlikely and described according to its anatomical position. Lytle $^{3}$ defined an impacted tooth as one that has failed to erupt into normal functional position beyond the time usually expected for such appearance. Andreasen et $\mathrm{al}^{4}$ gave a very lucid definition of impaction as a cessation of the eruption of a tooth caused by a clinically or radio graphically detectable physical barrier in the eruption path or by an ectopic position of the tooth. The most commonly impacted tooth in the oral cavity is indisputably the mandibular third molar. ${ }^{5}$ It accounts for $98 \%$ of all impacted teeth. ${ }^{6}$ According to the AAOMS report of the workshop on the management of patients with third molar teeth published in 1994, ${ }^{7}$ it was concluded that the progressive uprighting of third molars which are in a vertical position occurs up to the age of 25 and they advance to full eruption. Those which are unerupted may change position favorably or unfavorably till the middle of the third decade or perhaps longer. ${ }^{8-11}$

Various etiologic factors have been suggested for impacted mandibular third molars. These include the change in orientation or the position of the erupting third molar tooth, differential root growth between the mesial and distal roots as per Richardson. ${ }^{12,13}$ The size of the mandible or maxilla with the resultant lack of space and also the retarded maturation of third molars when compared to the skeletal growth of the jaws.

The current study aims to compare and assess the prevalence and pattern of impacted mandibular third molars in patients who reported to the Department of Oral and Maxillofacial Surgery, Orotta School of Dental Medicine and Orotta Medical and Surgical Referral Hospital, Asmara, Eritrea, East Africa. This is the first study regarding this subject in Eritrea.

\section{MATERIALS AND METHODS}

A retrospective study of patients was carried out from January 2009 to January 2014 in the Department of Oral and Maxillofacial Surgery of Orotta School of Medicine and Dental Medicine and Orotta Referral Medical and Surgical Hospital Asmara, Eritrea to assess the prevalence and pattern of impacted mandibular third molars in the Eritrean population. A total of 1,813 cases of patients aged 20 years and above were selected for the study. The clinical and radiographic records [orthopantomograms (OPGs)] of these patients were evaluated after the consent of patients and approval of the Ethical Research Committee of Orotta School of Medicine and Dental Medicine. The following parameters were considered for the study:

- Age group

- Gender

- Region
- Location of the impacted third molar (left, right, and bilateral)

- Angulation of the impacted tooth

- Position and level of the impacted tooth

- Associated pathological conditions, such as caries of second molar, pericoronitis, and periodontal pocket of the second molar, root resorption of second molar, cysts, and space infections

- The presence of any underlying systemic conditions like tuberculosis, cleft palate, and anemia.

The exclusion criteria for the study were as follows:

- Patients below 20 years of age

- Incomplete clinical records and poor quality of OPGs

- Pain in relation to impacted third molar, trismus, incomplete root formation of the third molar

- Severe systemic disease conditions, craniofacial anomalies or syndromes like achondroplasia, progeria, oxycephaly, cleidocranial dysostosis, and Down's syndrome

- Any previous trauma or pathology that may disrupt the alignment of third mandibular molars and history of extraction.

The inclusion criteria for the study were:

- Complete clinical record of patients

- Good quality panoramic radiographs

- Minimum age of 20 years

- Complete root formation of mandibular third molars. To avoid any discrepancy in judgment, all the OPGs were reviewed meticulously by a single examiner in the radiology laboratory with the help of a well-illuminated $X$-ray viewer and magnifying glass. They were analyzed for the angulation, position, and depth of impaction. Only teeth which had not attained functional occlusion were taken as impacted tooth. The angulation was assessed using Quek's adaptation of the Winter's classification (WC), which incorporated the use of an orthodontic protractor to quantify the angulation to reduce the errors associated with the evaluation by visual impression alone. The position and level of the impacted teeth were assessed using the Pell and Gregory Classification (PGC).

The analysis of the collected data was performed using the Pearson's chi-square test with the help of Statistical Package for Social Sciences (version 18.0) software.

\section{RESULTS}

A total of 276 out of 1,813 patients fulfilled the inclusion criteria and were included in the study. The average age of the patients was 30 years with a standard deviation of 6.839. The most number of cases were seen in the 20 to 30 years age group and amounted to $67.4 \%$, much higher than the 31 to 40 years age group which stood at $26.4 \%$. Females were found to be more affected by impaction with $53.3 \%$ cases compared with males who turned out 
Table 1: Age groups and frequency of impaction

\begin{tabular}{ll}
\hline Age group (years) & Frequency (\%) \\
\hline $20-30$ & $186(67.4)$ \\
$31-40$ & $73(26.4)$ \\
$>40$ & $17(6.2)$ \\
\hline Total & $276(100.0)$ \\
\hline
\end{tabular}

Table 3: Region and frequency of impaction

\begin{tabular}{ll}
\hline Region & Frequency (\%) \\
\hline Asmara & $220(79.7)$ \\
Others & $56(20.3)$ \\
\hline Total & $276(100.0)$ \\
\hline
\end{tabular}

Table 5: Winter's type of impaction and frequency as per age group

\begin{tabular}{lllll}
\hline \multirow{2}{*}{$\begin{array}{l}\text { Impaction } \\
\text { type } \\
\text { (Winter's) }\end{array}$} & \multicolumn{4}{c}{ Age group (years) } \\
\cline { 2 - 5 } & Frequency (\%) & $31-40$ & $>40$ & Total \\
\hline $\mathrm{D}$ & $28(15.1)$ & $7(9.6)$ & $2(11.8)$ & $37(13.4)$ \\
$\mathrm{H}$ & $9(4.8)$ & $2(2.7)$ & $1(5.9)$ & $12(4.3)$ \\
$\mathrm{O}$ & $3(1.6)$ & $0(0.0)$ & $0(0.0)$ & $3(1.1)$ \\
$\mathrm{M}$ & $98(52.7)$ & $45(61.6)$ & $3(17.6)$ & $146(52.9)$ \\
$\mathrm{V}$ & $48(25.8)$ & $19(26.0)$ & $11(64.7)$ & $78(28.3)$ \\
\hline
\end{tabular}

Chi-square $=16.851, \mathrm{df}=8, \mathrm{p}=0.032^{*}$ (significant) association between impaction type (Winter's) and age group was found to be statistically significant

to be involved in $46.7 \%$ of the cases (Tables 1 and 2). The greater number of patients $(79.7 \%)$ was observed to be from Asmara, while the remaining (20.3\%) were from the adjoining areas (Table 3 ).

Right side $(49.3 \%)$ was involved more than the left (42.4\%) with $50.4 \%$ of the males and $48.3 \%$ of the females having their right side affected. Statistically significant value was, however, observed when the side affected was put against the age groups included in the study ( $p=0.011) .51 .1 \%$ of the 20 to 30 years age group and $82.4 \%$ of the $>40$ years age group showed the involvement of the right side. On putting, the side affected against the region of the patients, it was seen that $49.5 \%$ from Asmara and $48.2 \%$ from the adjoining areas had their right side involved.

Mesioangular impaction WC was seen in $52.9 \%$ of the patients and was the most common type of angulation. When the gender of the patients was associated with the type of impaction WC, $56.5 \%$ of females and $48.8 \%$ of males were seen to have mesioangular impaction. On the contrary, when the age group was placed against the type of impaction WC, 52.7 and $61.6 \%$ in the 20 to 30 years and 31 to 40 years age groups respectively, had mesioangular impaction which was found to be statistically significant $(p=0.032$; Tables 4 and 5$)$. When relating the region of the patients to the type of impaction WC, $54.1 \%$ from
Table 2: Gender and frequency of impaction

\begin{tabular}{ll}
\hline Gender & Frequency (\%) \\
\hline Male & $129(46.7)$ \\
Female & $147(53.3)$ \\
\hline Total & $276(100.0)$ \\
\hline
\end{tabular}

Table 4: Winter's classification and angulation degrees as per Quek's adaptation taken for this study

\begin{tabular}{ll}
\hline & $\begin{array}{l}\text { Angulation (angle formed between } \\
\text { the intersected long axis of the }\end{array}$ \\
second and third molar)
\end{tabular}

Asmara had mesioangular impaction, while $48.2 \%$ from the other areas had the same type of impaction.

Class I position A PGC was seen in $59.8 \%$ of the patients and was the most common level of impaction. On relating the type of impaction PGC with the gender, it was found that $59.7 \%$ of the males and $59.9 \%$ of the females had class I position A type of impaction. Again when it was related with the age group of the patients, $55.9 \%$ in the 20 to 30 years age group, $71.2 \%$ in the 31 to 40 years age group, and $52.9 \%$ in the $>40$ years age group had class I position A type of impaction (Tables 6 and 7). When the region of the patients was related to the type of impaction PGC, 59.5 and $60.7 \%$ of the patients from Asmara and adjoining regions respectively, had class I position A type of impaction. The age group $v s$ sites of impaction is shown in Graph 1.

Systemic conditions of the patients were also considered and related to the type of impaction. Mesioangular and class I position A were the impaction types most often related to a systemic condition. Finally, when the type

Table 6: Pell and Gregory classification for assessing position and level of impacted tooth

Class I Space between ramus and distal surface of second molar greater than mesiodistal diameter of crown of impacted third molar

Class II Space between ramus and distal surface of second molar less than mesiodistal diameter of crown of impacted third molar

Class III All or most of the third molar is located within the ramus

Position A Occlusal plane of impacted third molar at or above the level of occlusal plane the second molar

Position B Occlusal plane of impacted third molar below the level of occlusal plane of the second molar but above the cervical line of second molar

Position C Occlusal plane of impacted third molar below the cervical line of second molar 
Table 7: Pell and Gregory type of impaction and frequency as per age group

\begin{tabular}{lllll}
\hline \multirow{2}{*}{$\begin{array}{l}\text { Impaction } \\
\text { type (Pell } \\
\text { and Gregory) }\end{array}$} & \multicolumn{5}{c}{ Age group (years) } \\
\cline { 2 - 5 } & Frequency (\%) & \multicolumn{3}{c}{$31-40$} \\
\hline C1PA & $104(55.9)$ & $52(71.2)$ & $9(52.9)$ & $165(59.8)$ \\
C1PB & $21(11.3)$ & $6(8.2)$ & $4(23.5)$ & $31(11.2)$ \\
C1PC & $6(3.2)$ & $1(1.4)$ & $0(0.0)$ & $7(2.5)$ \\
C2PA & $24(12.9)$ & $7(9.6)$ & $2(11.8)$ & $33(12.0)$ \\
C2PB & $18(9.7)$ & $5(6.8)$ & $2(11.8)$ & $25(9.1)$ \\
C2PC & $11(5.9)$ & $2(2.7)$ & $0(0.0)$ & $13(4.7)$ \\
C3PA & $1(0.5)$ & $0(0.0)$ & $0(0.0)$ & $1(0.4)$ \\
C3PB & $1(0.5)$ & $0(0.0)$ & $0(0.0)$ & $1(0.4)$ \\
\hline
\end{tabular}

Chi-square $=10.285, \mathrm{df}=14, \mathrm{p}=0.741$ (not significant). Association between impaction type (Pell and Gregory) and age group was found to be statistically nonsignificant in our study

of impaction was related to the associated pathologies very highly statistically significant results $(\mathrm{p}<0.001)$ were obtained. It was found that the mesioangular impaction was the type most commonly accompanied by any kind of associated pathology (Tables 8 and 9).

\section{DISCUSSION}

Eritrea is a country located in the horn of Africa with Asmara as the capital city. It is an ethnically diverse country with nine recognized ethnic groups in its population of around six million. This diversity in ethnicity is primarily due to its occupation by different racial groups

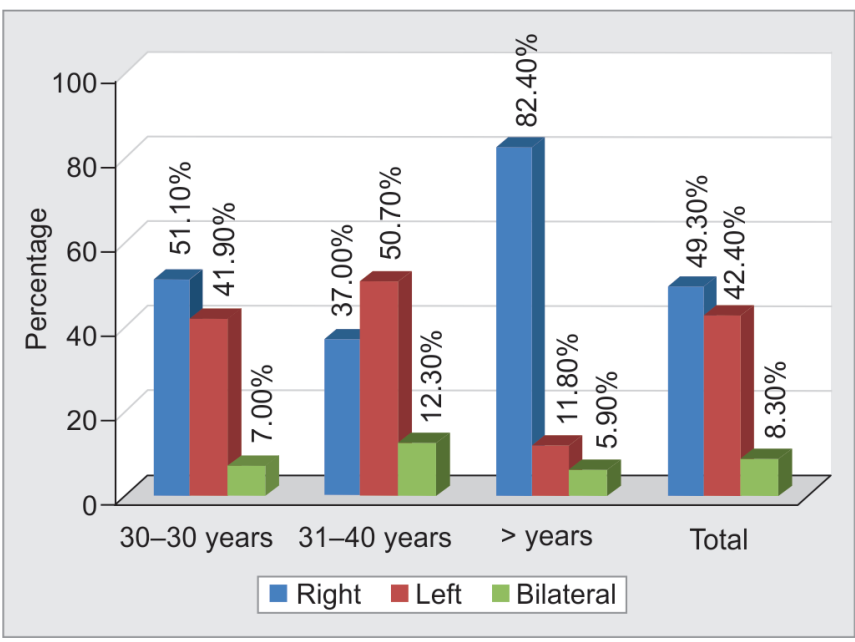

Graph 1: Association between sites included and age group was found to be statistically significant. Chi-square $=13.014$, $\mathrm{df}=4$, $p=0.011^{*}$ (Significant)

over its history, including the Italians, British, and the Ethiopians. Asmara is the largest settlement in the country and is also the most urbanized. The surrounding areas are less developed and are mainly agrarian. The current study is the first in the country and is the maiden report about the prevalence of mandibular impaction in Eritrean population.

The etiology of third molar impactions has been reviewed by various authors over the years. Lack of space, follicular collision, obstruction by physical/mechanical barriers, such as scar tissue, fibromatosis, compact bone,

Table 8: Winter's type of impaction and associated pathologies as per the classification

\begin{tabular}{|c|c|c|c|c|c|c|c|}
\hline \multirow{3}{*}{$\begin{array}{l}\text { Impaction type } \\
\text { (Winter's) }\end{array}$} & \multicolumn{7}{|c|}{ Pathologies associated } \\
\hline & None & Resorption & Pericoronitis & Cyst & Caries & Infection & Perio pocket \\
\hline & Frequency (\%) & & & & & & \\
\hline $\mathrm{D}$ & $14(41.2)$ & $3(25.0)$ & $11(8.6)$ & $0(0.0)$ & $4(20.0)$ & $0(0.0)$ & $5(9.6)$ \\
\hline $\mathrm{H}$ & $0(0.0)$ & $0(0.0)$ & $6(0.7)$ & $1(16.7)$ & $0(0.0)$ & $1(4.2)$ & $4(7.7)$ \\
\hline $\mathrm{O}$ & $1(2.9)$ & $1(8.3)$ & $0(0.0)$ & $0(0.0)$ & $0(0.0)$ & $1(4.2)$ & $0(0.0)$ \\
\hline M & $11(32.4)$ & $6(50.0)$ & $62(48.4)$ & $5(83.3)$ & $13(65.0)$ & $17(70.8)$ & $32(61.5)$ \\
\hline V & $8(23.5)$ & $2(16.7)$ & $49(38.3)$ & $0(0.0)$ & $3(15.0)$ & $5(20.8)$ & $11(21.2)$ \\
\hline
\end{tabular}

Chi-square $=62.482, \mathrm{df}=24, \mathrm{p}<0.001$ (highly significant) Association between impaction type (Winter's) and pathologies associated was found to be statistically very highly significant

Table 9: Pell and Gregory type of impaction and pathologies associated as per the classification

\begin{tabular}{llllllll}
\hline & \multicolumn{7}{c}{ Pathologies associated } \\
\cline { 2 - 7 } $\begin{array}{l}\text { Impaction type } \\
\text { (Pell and Gregory) }\end{array}$ & None & Resorption & Pericoronitis & Cyst & Caries & Infection & Perio pocket \\
\hline C1PA & $20(58.8)$ & $0(0.0)$ & $77(60.2)$ & $5(83.3)$ & $9(45.0)$ & $17(70.8)$ & $37(71.2)$ \\
C1PB & $6(17.6)$ & $0(0.0)$ & $15(11.7)$ & $0(0.0)$ & $4(20.0)$ & $0(0.0)$ & $6(11.5)$ \\
C1PC & $2(5.9)$ & $0(0.0)$ & $2(1.6)$ & $0(0.0)$ & $1(5.0)$ & $0(0.0)$ & $2(3.8)$ \\
C2PA & $5(14.7)$ & $0(0 . .0)$ & $20(15.6)$ & $0(0.0)$ & $0(0.0)$ & $5(20.8)$ & $3(5.8)$ \\
C2PB & $1(2.9)$ & $9(75.0)$ & $7(5.5)$ & $1(16.7)$ & $5(25.0)$ & $1(4.2)$ & $1(1.9)$ \\
C2PC & $0(0.0)$ & $1(8.3)$ & $7(5.5)$ & $0(0.0)$ & $1(5.0)$ & $1(4.2)$ & $3(5.8)$ \\
C3PA & $0(0.0)$ & $1(8.3)$ & $0(0.0)$ & $0(0.0)$ & $0(0.0)$ & $0(0.0)$ & $0(0.0)$ \\
C3PB & $0(0.0)$ & $1(8.3)$ & $0(0.0)$ & $0(0.0)$ & $0(0.0)$ & $0(0.0)$ & $0(0.0)$ \\
\hline
\end{tabular}

Chi-square $=147.67, \mathrm{df}=42, \mathrm{p}<0.001$ (highly significant). Association between impaction type (Pell and Gregory) and pathologies associated was found to be statistically very highly significant 
unattached mucosa, odontogenic cyst, and tumors are the common reasons. Svendsen and Maertens ${ }^{14}$ attributed lack of space and late third molar mineralization with early physical maturation as two of the causes of third molar impactions. The jaw space for accommodation of teeth is related to the jaw size, which is determined mainly by genetics. If physical maturity sets in before the mineralization of the third molar, then there will be less chance of influencing the remodeling process of the overlying bone. The role of genetics is now widely believed to be partly true since jaw shapes are an inherited trait and certain jaw shapes and sizes are associated with third molar impactions. Other major factors like the size of maxillary sinus and teeth are also equally important.

The prevalence of impaction in different populations ranges from 9.5 to $68 \%$ according to various authors. ${ }^{15-18}$ In our study, only $15.2 \%$ of the population seemed to be affected by this condition, which is comparatively less when compared to other studies. This may be due to larger jaw sizes of the people in the country although early mineralization and late physical maturity may also play a role. Growth is usually completed by 17 years of age. ${ }^{19}$ However, some change in angulation of the third molars may take place even up to the age of 32 years. ${ }^{20}$ This may give an explanation as to the decrease in impaction cases with advancing age that we find in our study; $67.4 \%$ of the cases were seen in the 20 to 30 years age group, whereas only $26.4 \%$ cases were found in the 31 to 40 years age group.

There is a difference in opinion regarding gender predilection to impaction. Many authors, ${ }^{15,17,21}$ including Brown et $\mathrm{al}^{22}$ and Montelius, ${ }^{23}$ are of the view that there is no sexual predilection when it comes to impaction. We found a higher percentage in females as compared with males in our study, which is in agreement with other authors like Murtomaa et $\mathrm{al}^{24}$ and Hugoson and Kugelberg. ${ }^{25}$ The higher frequency in females may be explained by the fact that growth of the jaw in females stops when the third molars begin erupting whereas in males the growth continues even after eruption. ${ }^{26}$ Furthermore, the end of the growth spurt in females is related to their onset of menarche. This has been found to arrive earlier by 2.8 years in the modern world owing to intrinsic factors like living conditions and lifestyle. ${ }^{27}$ This may offer a relationship of early physical maturity and late mineralization of third molars to the higher frequency in females.

Asmara being the capital city has more opportunities for employment and provides a better lifestyle compared with the rest of Eritrea, which is overall a developing country. This led to the migration of people from various places across the country to Asmara and getting used to the new environment and habits. The urbanized lifestyle through time brought about a change in diet to a more refined one which might have caused less stimulation to the growth of jaws compared to the earlier crude village diet. The research studies by $\mathrm{Begg}^{28}$ on primitive skulls have shown a clear indication about the relation of civilization and dental attrition. Lombardi ${ }^{29}$ in 1982 from his studies came to the conclusion that the crowding of teeth is more common in technologically advanced population than in primitive ones. He observed that the interproximal wearing of tooth is associated with the chewing force required by the diet. According to this theory, the coarse diet required more masticatory forces which led to the lateral movement of the tooth relative to each other and proximal wear. In the modern society, since the diet is more refined, the masticatory forces are less and interproximal attrition or wear is absent. Taking this as a possible reason, we may infer from our study why the cases were probably more from Asmara when compared to the surrounding areas.

We found that the right side was affected more than the left in this population. Bilateral cases were relatively low $(8.3 \%)$. The reason for this is difficult to speculate but maybe related to genetics although further studies in this regard are required for a better conclusion. The finding was in contrast to other studies like Quek et $\mathrm{al}^{18}$ who found that bilateral cases were more common than unilateral, but Dachi and Howell ${ }^{21}$ from their studies concluded that both bilateral and unilateral cases occurred with equal frequency.

Mesioangular impaction was found to be the most common angulation in our study which is in line with other studies like those of Quek et $\mathrm{al}^{18}$ and Kramer and Williams. ${ }^{30}$ Other studies like the one by Hugoson and Kugelberg $^{25}$ found vertical impaction to be more common than mesioangular. It is to be kept in mind that such comparisons of angulations are difficult to make considering the classification systems that have been used in various studies and also the methods used to assess them. We tried to relate the angulation to the sex, age and region of the subjects and found that the mesioangular impaction was more common in females, in the 20 to 40 age range ( $\mathrm{p}=0.032)$ and in Asmara.

Class I position A was the most common position and level in our study. As with angulations the problem in comparing with the results of other others lies in the fact that every author uses different classification criteria. However, we would like to point out that class I position $\mathrm{A}$ is considered to be one of the most uncomplicated forms of impaction. Considering our earlier finding of the decreased prevalence in the country, it may be inferred that currently the population is still in the beginning of the transformation to factors that lead to impaction and may continue to increase in complexity with time and change 
in conditions. Again, we tried to relate the position and level of impaction to the sex, age, and region and found class I position A to occur with almost equal frequency with respect to the sex and region, although ages 31 to 40 years showed more cases with this type of impaction.

Certain acquired systemic conditions and developmental disturbances lead to retardation in the growth of an individual which can subsequently lead to impaction. Examples of such conditions include Syphilis, tuberculosis, anemia, malnutrition, cleft palate, rickets and endocrine dysfunctions. In our study, we found impacted third molars in patients with cleft palate, tuberculosis, and anemia. Some of the most common pathologies associated with impacted third molars include dentigerous cysts, pericoronitis, and pocket formation. When we attempted to relate the type of impaction which was more commonly associated with pathologies, mesioangular impaction emerged to be the more frequent type.

\section{LIMITATIONS}

This is the first ever study conducted in Eritrea to evaluate the prevalence and pattern of mandibular third molar impactions. The etiological factors related to impacted mandibular third molars in Eritrea still needs to be reevaluated. Hence, further studies in this regard have to be emphasized. In this study, we have taken into account only those patients who had reported to Orotta Medical and Surgical Referral Hospital and Orotta School of Dental Medicine. Although Orotta Medical and Surgical Hospital is the main referral hospital in the country, the similar condition from far-located rural areas of the population still needs a detailed survey.

\section{CONCLUSION}

The prevalence of mandibular impaction was less in Eritrea compared with other populations. In our study, only $15.2 \%$ of the population seemed to be affected by the condition which is comparatively less when compared to other studies from different countries and regions. The majority of the cases were from Asmara the largest city in the country rather than from adjoining less developed areas. Mesioangular impaction WC was the most common type of angulation. Class I position A PGC was the most common level of impaction. The study is the first of its kind in the country and provides the baseline data for the prevalence and pattern of mandibular impaction in the Eritrean population.

\section{ACKNOWLEDGMENT}

The authors hereby acknowledge Dr Lainesh, Head of Oral and Maxillofacial Unit, Orotta Referral Medical and Surgical Hospital Asmara, Eritrea for the cooperation and support rendered to conduct this study.

\section{REFERENCES}

1. Rounds CE. Principles of exodontia. 2nd ed. St. Louis, MO: CH Mosby; 1962. 388 p.

2. William HA. Oral and maxillofacial surgery. 5th ed. Philadelphia, PA: WB Saunders; 1975. 1859 p.

3. Lytle JJ. Indications and contraindications for removal of the impacted tooth. Dent Clin North Am 1979 Jul;23(3):333-346.

4. Andreasen JO, Petersen JK, Laskin DM. Text book and colour atlas of tooth impactions. 1st ed. Copenhagen: Munksgaard; 1997. $542 \mathrm{p}$.

5. Peterson LJ. Principles of management of impacted teeth. In: Eills E, Huup JR, Tucker MR, editors. Contemporary oral and maxillofacial surgery. 4th ed. New York: Mosby; 2003. p. 184-213.

6. Badawi Fayad J, Levy JC, Yazbeck C, Cavezian R, Cabanis EA. Eruption of third molars: relationship to inclination of adjacent molars. Am J Orthod Dentofacial Orthop 2004 Feb;125(2):200-202.

7. AAOMS. Report of workshop on the management of patients with third molar teeth. J Oral Maxillofac Surg 1994 Oct;52(10):1102-1112.

8. von Wowern N, Nielsen HO. The fate of impacted lower third molars after the age of 20. A four-year clinical follow-up. Int J Oral Maxillofac Surg 1989 Oct;18(5):277-280.

9. Garcia RI, Chauncey HH. The eruption of third molars in adults: a 10-year longitudinal study. Oral Surg Oral Med Oral Pathol 1989 Jul;68(1):9-13.

10. Rantanen A. The age of eruption of third molar teeth. Acta Odontol Scand 1961;25(Suppl 1):48.

11. Sewerin I, von Wowern N. A radiographic four-year followup study of asymptomatic mandibular third molars in young adults. Int Dent J 1990 Feb;40(1):24-30.

12. Richardson ME. The effect of mandibular first premolar extraction on third molar space. Angle Orthod 1989 Winter;59(4):291-294.

13. Richardson ME. Pre-eruptive movements of the mandibular third molar. Angle Orthod 1978 Jul;48(3):187-193.

14. Svendsen H, Maertens JK. Etiology of third molar impaction. In: Andreasen JO, Petersen JK, Laskin DM, editors. Textbook and color atlas of tooth impactions. Copenhagen: Munksgaard; 1997. p. 223-227.

15. Lima CJ, Silva LC, Melo MR, Santos JA, Santos TS. Evaluation of the agreement by examiners according to classifications of third molars. Med Oral Patol Oral Cir Bucal 2012 Mar;17(2):e281-e286.

16. Hattab FN, Rawashdeh MA, Fahmy MS. Impaction status of third molars in Jordanian students. Oral Surg Oral Med Oral Pathol Oral Radiol Endod 1995 Jan;79(1):24-29.

17. Haidar Z, Shalhoub SY. The incidence of impacted wisdom teeth in a Saudi community. Int J Oral Maxillofac Surg 1986 Oct;15(5):569-571.

18. Quek SL, Tay CK, Tay KH, Toh SL, Lim KC. Pattern of third molar impaction in a Singapore Chinese population: a retrospective radiographic survey. Int J Oral Maxillofac Surg 2003 Oct;32(5):548-552.

19. Fielding AF, Douglass AF, Whitley RD. Reasons for early removal of impacted third molars. Clin Prev Dent 1981 Nov-Dec;3(6):19-23.

20. Ventä I, Turtola L, Ylipaavalniemi P. Radiographic follow-up of impacted third molars from age 20 to 32 years. Int J Oral Maxillofac Surg 2001 Feb;30(1):54-57. 
21. Dachi SF, Howell FV. A survey of 3,874 routine full-mouth radiographs. I. A study of retained roots and teeth. Oral Surg Oral Med Oral Pathol 1961 Aug;14:916-924.

22. Brown LH, Berkman S, Cohen D, Kaplan AL, Rosenberg M. A radiological study of the frequency and distribution of impacted teeth. J Dent Assoc S Afr 1982 Sep;37(9):627-630.

23. Montelius GA. Impacted teeth: a comparative study of Chinese and Caucasian dentitions. J Dent Res 1932;12(6):931-938.

24. Murtomaa H, Turtola L, Ylipaavalniemi P, Rytömaa I. Status of the third molars in the 20- to 21-year-old Finnish university population. J Am Coll Health 1985 Dec;34(3):127-129.

25. Hugoson A, Kugelberg CF. The prevalence of third molars in a Swedish population. An epidemiological study. Community Dent Health 1988 Jun;5(2):121-138.
26. Hellman M. Our third molar teeth: Their eruption, presence and absence. Dent Cosmos 1936 Jul;78(7):750-762.

27. Thomas F, Renaud F, Benefice E, de Meeüs T, Guegan JF. International variability of ages at menarche and menopause: patterns and main determinants. Hum Biol 2001 Apr;73(2):271-290.

28. Begg PR. Stone age man's dentition. Am J Orthod 1954 Apr;40(4):298-312, 373-383 and 462-475.

29. Lombardi AV. The adaptive value of dental crowding: a consideration of the biologic basis of malocclusion. Am J Orthod 1982 Jan;81(1):38-42.

30. Kramer RM, Williams AC. The incidence of impacted teeth. A survey at Harlem hospital. Oral Surg Oral Med Oral Pathol 1970 Feb;29(2):237-241. 